\title{
UMA CONTRIBUIÇÃO AO DEBATE SOBRE 0 DESENVOLVIMENTO REGIONAL DO NORDESTE ${ }^{1,2}$
}

\author{
Bruno de Oliveira Cruz ${ }^{3}$ \\ Carlos Wagner de Albuquerque Oliveira ${ }^{4}$ \\ César Nunes de Castro ${ }^{5}$ \\ Márcio Bruno Ribeiro 6 \\ Rafael H. M. Pereira ${ }^{7}$
}

\section{INTRODUÇÃO}

O Brasil está entre os países mais desiguais do mundo, e esta desigualdade expressa-se também em níveis regionais. Entre os fatos mais comuns indicadores das desigualdades entre regiōes, costuma-se destacar que o Nordeste tem $27 \%$ da população e uma participação no produto interno bruto (PIB) de 14\%, ou seja, o PIB per capita da região representa aproximadamente metade do PIB per capita brasileiro.

Como forma de enfrentar tais desequilíbrios, a Constituição Federal de 1988, em seu art. 3o, ressalta que um dos objetivos da República Federativa seria exatamente a redução das desigualdades regionais. Assim, seria papel do Estado brasileiro desenvolver açóes para reduzir estas desigualdades. É importante advertir, contudo, que a concentração de atividades econômicas no território representa mais do que uma exceção, mostra-se como uma regra ao longo da história e em diferentes locais do mundo.

Este trabalho trata de alguns aspectos da economia do Nordeste e dá sugestóes, de maneira mais ampla, para o debate sobre políticas com foco no desenvolvimento da região. Os gestores e policy makers devem levar em conta que a convergência de níveis de renda é, no melhor dos casos, muito lenta, e simulaçóes com choques positivos de produtividade mostram que o Nordeste cresceria a taxas mais elevadas que a média nacional. Contudo, após

\footnotetext{
1. DOI: http://dx.doi.org/10.38116/brua22art1

2. Este artigo é fruto de um esforço coletivo dos autores. Houve envolvimento de diversas coordenações da Diretoria de Estudos e Políticas Regionais, Urbanas e Ambientais (Dirur) do Ipea e de técnicos do Ipea, mas a responsabilidade final do documento, obviamente, é somente dos autores, assim como todos os erros e omissões remanescentes. Os autores agradecem as sugestões e discussões com Aristides Monteiro Neto, Cleandro Krause, Fernanda de Negri, Flávio Gonçalves, Gesmar Rosa dos Santos, Gustavo Luedemann, José Feres, Luiz Esteves, Mauro Oddo e Nelson Zackseski.

3. Técnico de planejamento e pesquisa na Dirur/lpea.

4. Técnico de planejamento e pesquisa na Dirur/lpea.

5. Especialista em políticas públicas e gestão governamental lotado na Dirur/lpea.

6. Coordenador de estudos regionais e federativos na Dirur/lpea.

7. Chefe da Assessoria de Métodos Quantitativos da Dirur/lpea.
} 
dez anos, a renda per capita da região estaria em $60 \%$ da renda observada no país, isto é, um plano em nível nacional bem-sucedido de melhoria da produtividade não seria suficiente para que a diferença entre o PIB do Nordeste e o PIB nacional chegasse ao limite mínimo de 75\%, parâmetro utilizado pela Uniāo Europeia para definir regiôes-alvo de política regional.

Assim, o argumento deste artigo é de que existem justificativas para o desenvolvimento de políticas focadas em territórios específicos, não somente relacionadas à política regional explícita, que teriam importante efeito sobre a área. Políticas urbanas, por exemplo, têm sido apontadas como fonte de melhoria de produtividade em cidades. ${ }^{8}$ Argumenta-se, também, que existem diferentes contextos dentro da região. Por exemplo, existem regiôes no semiárido onde açôes pontuais de extensionismo e assistência rural podem auxiliar a mitigar riscos e elevar produtividade, com retornos para produtores e sociedade e sistema de crédito. Esta ação poderia ser desenhada com um programa, no qual a redução de risco para o sistema de crédito agrícola pudesse financiar em parte a assistência e o extensionismo, reduzindo em muito o custo fiscal do programa.

Seguindo a linha de compartilhamento de riscos, argumenta-se também que, a partir da legislação já existente, seria possível ampliar o sistema de compartilhamento de instalaçôes físicas, com vistas ao aumento da interação entre universidade e empresa na busca de inovação. Desse modo, instrumentos de políticas regionais poderiam ser utilizados na implementação de instalaçóes compartilhadas, aliados a projetos de pesquisa bem definidos, sendo que os frutos dos projetos ou inovaçôes resultantes do trabalho de pesquisa remunerariam os parceiros, inclusive o Estado. Outro instrumento bastante viável seria a utilizaçấo do poder de compra dos governos locais para incentivar pesquisas e desenvolvimento em tecnologia na região, que poderia ser combinado com o uso compartilhado de instalaçôes. Além disso, existem iniciativas bem-sucedidas na região em energia renovável. Alega-se que tais investimentos devem ser ampliados, assim como projetos com foco em regiôes específicas, como a iniciativa do Ministério do Desenvolvimento Regional (MDR), nas Rotas de Integração Nacional, com potencial de melhoria efetiva na regiáo.

Portanto, o artigo elenca uma série de sugestôes complementares a açôes já em curso. Deve-se lembrar que a Superintendência do Desenvolvimento do Nordeste (Sudene) já elaborou o Plano Regional de Desenvolvimento do Nordeste (PRDNE) em conjunto com o MDR e representantes da região. Assim, o intuito aqui é contribuir para o debate, fugindo da pretensão de propor um plano de desenvolvimento completo.

As políticas regionais tradicionais têm sido criticadas pela ausência de coordenaçáo entre os diversos atores. Há um descolamento entre os objetivos gerais propostos pelo plano de ação ou planos de desenvolvimento e os instrumentos da política, notadamente os fundos constitucionais (Coelho, 2017; TCU, 2009). O artigo traz algumas sugestôes para redirecionamento da política regional e integração de outras açóes como medidas de aprimoramento dos ganhos de aglomeração, em nível local. Para uma efetiva alteração da estrutura produtiva no Nordeste, há que se refletir que são necessários investimentos em tecnologia, políticas de difusão de tecnologia e assistência técnica, no meio rural, por exemplo, para melhoria da produtividade e expansão da renda local.

Este trabalho está organizado em cinco seçôes, contando com esta introdução e as consideraçóes finais. Na sequência, são apresentados os fatores que se destacaram em

8. Sobre o assunto, ver, por exemplo, Ferreyra e Roberts (2018) e Prager e Thisse (2009). 
momentos recentes da economia do Nordeste. A seção 3, por sua vez, discute avanços recentes na relação entre políticas regionais e bem-estar. Na seção 4, por fim, estão listadas algumas sugestôes para o debate do desenvolvimento regional na região em questão, a partir do contexto apesentado na seçáo 2 .

\section{CONTEXTO RECENTE DA ECONOMIA DO NORDESTE}

Entre alguns fatos relevantes do desemprenho socioeconômico do Nordeste, pode-se citar o crescimento da economia local acima da economia nacional, antes da recessão de 2014-2016, ${ }^{9}$ a melhoria de indicadores educacionais, ainda que os níveis da região estejam abaixo da média nacional, ${ }^{10}$ a expansão da rede de universidades federais e institutos federais, o crescimento de cidades médias na regiấo e o crescimento da indústria e de serviços acima da média nacional.

A despeito da perda de participação no PIB da indústria de transformação, em nível nacional, há uma ampliação da sua participação no PIB da região. $\mathrm{O}$ crescimento da indústria de transformação concentra-se em setores tradicionais intensivos em trabalho ou em recursos naturais. A produtividade do trabalho na indústria também cresceu, mas basicamente no mesmo ritmo da economia nacional (Monteiro Neto e Silva, 2018). A agricultura no Nordeste é bastante heterogênea, com setores dinâmicos do agronegócio na área do chamado Matopiba ${ }^{11}$ dividindo espaço com a produção tradicional e estagnada em algumas regióes, como a cana-de-açúcar e agricultura de subsistência no semiárido. Também se observam baixo uso de tecnologia ou presença reduzida de assistência técnica e propriedades relativamente menores no Nordeste em relação ao restante do país. A escassez de água e a qualidade mais baixa dos solos fazem com que a produtividade da agricultura fique aquém das possibilidades de produção, mesmo considerando as condições climáticas adversas de algumas regióes. ${ }^{12}$

O turismo possui uma participaçáo pequena na economia brasileira, e o Nordeste não é exceção. No entanto, há dois fatos interessantes no comportamento desse setor no Nordeste: os empregos formais cresceram mesmo durante a crise; e, comparando o setor relativamente ao restante da economia nordestina, o turismo tende a ser mais formalizado do que os demais setores. ${ }^{13}$

Outro aspecto de destaque na dinâmica recente do Nordeste é o crescimento mais acelerado nos próximos anos da população em idade ativa, em relação ao observado em nível nacional. Apesar do Nordeste seguir a tendência de envelhecimento da população, há essa janela demográfica até metade da próxima década. A população em idade ativa, em contrapartida, começará a cair antes do projetado para o Brasil, devido ao saldo líquido negativo da migração do Nordeste.

\footnotetext{
9. Alguns indicadores apontam para o fato de que a recessão no Nordeste foi ainda maior do que em nível nacional. A menor diversificação da economia aliada a uma informalidade acima da média nacional, além da redução de transferência do Fundo de Participação dos Estados e do Distrito Federal (FPE) e do Fundo de Participação dos Municípios (FPM), atuam como um canal de transmissão da recessão de regiões mais desenvolvidas para o Nordeste.

10. Um exemplo dessa melhoria, de acordo com a Pesquisa Nacional por Amostra de Domicílios do Instituto Brasileiro de Geografia e Estatística (Pnad/IBGE), refere-se ao número médio de anos de estudo da população com 25 anos ou mais. Em 1981, um cidadão nordestino tinha 60\% da média de anos de estudo de um brasileiro; em 2014, esta relação cai para $80 \%$, em um período de crescimento da escolaridade média no Brasil.

11. Acrônimo para designar o conjunto formado pelos estados do Matogrosso, Tocantins, Piauí e Bahia.

12. Com relação ao desempenho da agricultura na região, sugere-se a consulta de Castro $(2012 ; 2018)$.

13. Ao leitor interessado no setor de turismo, a principal referência é o projeto desenvolvido pelo Ipea, em especial o Sistema de Informações sobre o Mercado de Trabalho no Setor Turismo (SIMT), disponível em: <http://www.ipea.gov.br/ extrator/simt.html>.
} 
Ademais, é importante destacar que intervençóes simples e criativas, como o Programa Cisternas ou mesmo o Programa Nacional de Fortalecimento da Agricultura Familiar (Pronaf), apresentaram impacto positivo e conseguiram mitigar riscos de seca e choques adversos de produtividade (Branco e Féres, 2019; Castro, Resende e Pires, 2014).

Não obstante essa recente dinâmica positiva, a economia nordestina ainda enfrenta diversos desafios que devem ser considerados na discussão do desenvolvimento da regiáo. A seguir são listados alguns desses grandes desafios.

1) Desigualdade ainda elevada: mesmo crescendo acima da média do Brasil, a região Nordeste ainda levaria cinquenta anos para atingir $75 \%$ da média do PIB nacional, limite considerado pela União Europeia (UE) como objetivo de redução de desigualdades regionais (Cruz, 2014).

2) Agropecuária bastante heterogênea: há expansão em áreas exportadoras do agronegócio e expansão de fruticultura irrigada, que dividem espaço com setores tradicionais estagnados como a cana-de-açúcar e uma agricultura familiar quase de subsistência. Além disso, há baixa qualificação e grande diferença entre níveis educacionais das áreas rurais e urbanas.

3) Desemprego mais alto e informalidade maior que a média brasileira: somente no Ceará e na Paraíba observa-se que a taxa de desocupação medida pela Pesquisa Nacional por Amostra de Domicílios Contínua (Pnad Contínua) está abaixo da taxa registrada no país. Em alguns estados, como na Bahia, a taxa de desocupação chega a ser 5,3 pontos percentuais (p.p.) acima da média brasileira.

4) Riscos climáticos e qualidade do solo: o semiárido tem alta taxa de evapotranspiraçáo e baixo índice pluviométrico, além de solos com pouca profundidade.

5) Menor qualidade de ensino: tem-se o pior desempenho em testes padronizados ou mesmo no Índice de Desenvolvimento da Educação Básica (IDEB), ainda que haja algumas exceçôes, como o bom desempenho do Ceará no IDEB. Há também maior defasagem idade-série no Nordeste em relação ao Brasil - que já apresenta índices elevados de defasagem idade-série - e alta evasão nos estados dessa região, em especial nos anos finais do ensino médio (Brasil, 2019).

6) Pobreza e concentração de níveis baixos de escolaridades em diversas áreas.

7) Articulação entre diversos entes federados ainda complexa, a despeito de esforços recentes.

8) Crise fiscal.

\section{POLÍTICA REGIONAL E BEM-ESTAR}

Estudos da chamada nova geografia econômica, em especial a partir do fim dos anos $1980 \mathrm{e}$ início dos 1990, têm discutido a estabilidade e a presença das aglomeraçôes econômicas ao longo da história e em diversos países e regiōes. Esses estudos têm mostrado, entre outros resultados, que a presença de retornos crescentes e os ganhos de aglomeraçáo incentivam a concentração de atividades e tornam cidades e regiôes metropolitanas verdadeiros motores de inovação, crescimento e ganhos de produtividade, bem como polos de atração de novas atividades.

Um fato estilizado bastante consolidado na literatura é a constatação de que empresas localizadas em cidades maiores tendem a ser mais produtivas. Assim, a arbitragem entre custo de transporte, ganhos de aglomeração e efeitos negativos de congestionamento condiciona a distribuição das atividades no território. A presença destas falhas de mercado e diversos 
problemas de coordenação abrem espaço para se pensar o desenho de políticas públicas com efetivos ganhos de bem-estar. ${ }^{14}$

Ainda que a discussão seja bastante ampla, diversos autores argumentam que o objetivo primordial deveria ser o de condicionar as políticas às pessoas e não se pensar em intervençôes com foco em regiōes, pois há o risco de políticas focadas no território serem pouco efetivas ou mesmo capturadas por uma elite local, levando a poucas mudanças na regiáo-alvo. ${ }^{15}$ Avanços teóricos recentes, no entanto, rebatem tais argumentos mostrando que políticas focadas no território podem ter impactos positivos sobre o bem-estar de moradores de "regiōes perdedoras" deste processo de aglomeração. ${ }^{16}$

Em 2009, o Banco Mundial publicou, em seu Relatório sobre o Desenvolvimento Mundial, uma lista de sugestôes, reconhecendo todos os avanços teóricos e empíricos da nova geografia econômica (Banco Mundial, 2009). Foram separadas diversas intervençóes, condicionando-as a uma classificação baseada em três níveis: densidade, distância e divisão. A lista de intervençôes compreende melhoria em instituiçôes, infraestrutura, políticas cegas em relação ao espaço e políticas focadas no território. No entanto, diversas sugestôes do Banco Mundial são criticadas por serem demasiadamente deslocadas do contexto local e por darem excessiva atenção para a concentração de atividades e não considerarem em maior detalhe as regiôes perdedoras. ${ }^{17}$

Mesmo em um contexto como o do relatório do Banco Mundial, entretanto, há espaço para intervençôes focadas localmente. Os resultados atuais mostram que existe uma espécie de curva de Kuznets, em forma de sino, relacionando a concentração de atividades e o custo de transporte entre as regióes. Em níveis intermediários de custo de transporte, a concentração espacial estaria em um ponto máximo. Com a contínua redução desses níveis de custo, a excessiva concentração gera efeitos negativos de congestionamento ou mesmo preços de insumos mais elevados, resultando, portanto, em estímulo para uma desconcentração de atividades (Prager e Thisse, 2009). Conforme constatam Prager e Thisse (2009), essa desconcentração, no entanto, pode ser muito lenta, podendo haver ganhos de bem-estar de políticas de desenvolvimento regional bem desenhadas, seja de transferência de renda, seja de estímulo à relocalização de atividades (Charlot et al., 2006).

Tendo como premissa esses resultados tanto empíricos quanto teóricos, a próxima seção apresenta sugestôes de maneira mais ampla para o debate sobre as intervençôes na regiáo, considerando ser possível, além de necessário, algum grau de intervenção com foco local.

\section{SUGESTÕES GERAIS}

O Nordeste tem se beneficiado da desconcentração industrial do Sudeste, ainda que em menor escala que regiôes como o Centro-Oeste e o Sul; há, ainda, expansão da fronteira agrícola nas áreas de Cerrado do Nordeste; e a região crescia acima da média brasileira antes da grande recessão de 2014-2016. Contudo, a produtividade média do trabalho na indústria e em grande parte na agricultura fica abaixo da média nacional, e a expansão da indústria concentrou-se em setores intensivos em recursos naturais ou trabalho. Mesmo crescendo acima da média da economia nacional, parte dos estados do Nordeste ainda levaria pelo

\footnotetext{
14. Conferir os trabalhos de Ferreyra e Roberts (2018) e Prager e Thisse (2009) para mais informações sobre o assunto. 15. Ver, por exemplo, Pessoa (1997).

16. Ver trabalho de Charlot et al. (2006), por exemplo.

17. Ver Prager e Thisse (2009).
} 
menos cinquenta anos para atingir 75\% do nível per capita nacional, e alguns, como Alagoas, levariam mais de 1 mil anos para atingir essa meta.

Ademais, a trajetória tendencial projetada pelo modelo International Futures aponta para um crescimento médio do produto per capita de apenas 0,6\% para o Brasil e o Nordeste, $1,3 \%$ de 2015 a $2030 .{ }^{18} \mathrm{Em}$ um cenário alternativo, com elevação da produtividade, melhoria da gestão pública e ampliação em infraestrutura, o crescimento do PIB per capita na região atingiria $2,08 \%$ de média anual, isto é, ganho de 0,75 p.p. na média anual em relação ao cenário-base. Assim, no melhor dos cenários com melhoria de produtividade, eficiência do governo, aumento de matrículas no ensino superior, após uma década, o nível de PIB per capita da região estaria abaixo de $60 \%$ do PIB per capita nacional, somente Pernambuco atingiria $60 \%$ deste PIB.

Finalmente, em termos conjunturais, deve-se ter em conta que o hiato do produto e a taxa de desocupação da economia brasileira e da economia nordestina estão em níveis extremamente elevados por períodos muito longos, o que pode levar à reduçáo da taxa de crescimento do PIB potencial, devido, por exemplo, à depreciação do capital humano, dificuldade de reinserção de trabalhadores no mercado de trabalho, perda de conhecimento e habilidades acumuladas, entre outros. Há também uma janela demográfica com a população em idade ativa crescendo mais no Nordeste do que no restante do país, e em termos percentuais a participação da população de 15 a 64 anos ficaria maior no Nordeste do que no Brasil e no Sudeste. Náo obstante essa trajetória positiva nos próximos anos, a população nessa idade irá começar a apresentar decréscimo cinco anos antes da economia brasileira, devido ao processo de migração.

Dessa forma, o desafio que se coloca para os gestores e policy makers está relacionado ao fato de a convergência de níveis de renda ser lenta, e mesmo um choque de produtividade nacional sozinho não será suficiente para alterar de maneira decisiva o quadro de atraso relativo da regiáo Nordeste nos próximos dez anos, de acordo com o modelo de simulaçáo do Pardee Center. Diante desse cenário, é importante se pensar em políticas de recuperação cíclicas. A utilização mais agressiva da política monetária, em nível nacional, na condução macroeconômica, é o primeiro passo importante. Em nível regional, a possibilidade de recuperação de investimentos públicos também pode ter impacto positivo numa retomada cíclica da economia mais acelerada. ${ }^{19}$

Ao mesmo tempo, ao se pensar intervençôes direcionadas à regiáo, deve-se lembrar que as políticas regionais tradicionais têm recebido criticadas por sua ausência de coordenação entre os agentes locais e mesmo entre órgáos governamentais. Os instrumentos da política, em grande medida, estão descolados dos objetivos gerais propostos pelo plano de ação ou planos de desenvolvimento (Coelho, 2017; TCU, 2009). Para uma efetiva alteração da estrutura produtiva no Nordeste, há que se refletir que são necessários investimentos em tecnologia, políticas de difusão de tecnologia e assistência técnica, no meio rural, por exemplo, para melhoria da produtividade e expansão da renda local.

18. Para mais informações, ver neste boletim o artigo de autoria de Carlos Wagner de Albuquerque Oliveira e Bruno de Oliveira Cruz, intitulado Simulando impactos regionais de choques de produtividade: o caso da região Nordeste.

19. Importante destacar que trabalho recente do Ipea, de Zackseski e Oliveira (no prelo), analisando a distribuição regional dos investimentos, aponta que a redução dos investimentos públicos foi menos sentida na região Nordeste, pelo menos até 2016, em parte pela manutenção de investimentos em projetos, como o de transposição do rio São Francisco. 
A melhoria da conexão entre regióes pode igualmente ter impactos significativos. Há carências de infraestrutura e a necessidade de execução de pequenas obras de conexôes vicinais no interior com impacto relevante tanto em áreas de Cerrado como no semiárido e na Caatinga, ou mesmo no Matopiba. Outra carência de infraestrutura encontra-se na interligação de áreas produtoras de energia limpa e renovável à rede geral. Simultaneamente, é preciso ter em mente que as políticas sociais, de transferência de renda e de manutençáo do valor do salário mínimo, não focadas no território, dada a concentração da pobreza em algumas áreas da regiáo, possuem um forte impacto regional.

Portanto, sugestôes gerais de ação incluem políticas horizontais como foco mais geral em vários setores: ações de melhoria dos serviços e bens, ampliação de benefícios das economias de aglomeração e mitigação de efeitos negativos de congestionamento (políticas de gestão urbana, mobilidade e saneamento), utilização de instrumentos disponíveis para ampliação da participação do setor privado em pesquisa, desenvolvimento e inovação (PD\&I), dado o compartilhamento de riscos entre o setor privado e público, ou utilização das chamadas encomendas tecnológicas (ETECs).

Concomitantemente, em regióes mais carentes, podem ser pensadas intervençôes políticas verticais, mais focadas setorialmente, como o programa Rotas de Integração Nacional, de integração e identificação de arranjos produtivos locais (ação já desenvolvida pelo MDR), ou o incentivo ao cooperativismo e à associação de produtores com articulação das produtivas já existentes, incluindo o trabalho de extensão e assistência rural.

\subsection{Ampliação de ganhos de aglomeração e mitigação de efeitos negativos de congestionamento}

Em trabalho recente do Banco Mundial, Ferreyra e Roberts (2018) mostram que as cidades da América Latina seguem fato empírico bastante sólido na literatura: cidades maiores tendem a ser mais produtivas. Diversos fatores explicam essa constatação: uma maior oferta e em qualidade superior de bens e serviços para as firmas; um mercado de trabalho amplo e com uma possibilidade de melhor matching entre vagas e qualificaçóes específicas; maior concentração de trabalhadores qualificados; e maior fluxo de ideias e difusão mais rápida de inovaçôes, gerando os chamados ganhos de aglomeração. ${ }^{20}$ Assim, políticas que ampliem essas externalidades positivas e ganhos de conhecimento têm impacto generalizado sobre o bem-estar e resultam em crescimento econômico. Mitigar e reduzir custos de congestionamento e ampliar o acesso de regióes menos carentes têm um duplo retorno: melhoria do matching entre vagas e qualificação de trabalhadores e geração de ganhos de produtividade na redução do deslocamento casa-trabalho.

O Ipea tem uma ampla agenda de pesquisa nessa área que inclui regiôes metropolitanas do Nordeste, por exemplo, Fortaleza e Recife. Denominado Acesso a Oportunidades, o projeto tem como base duas grandes questôes: quantos postos de trabalho um cidadão consegue acessar em menos de uma hora usando transporte público? E quanto tempo se leva para chegar até o posto de saúde ou escola mais próxima da sua casa? As respostas a essas perguntas dependem diretamente das políticas de transporte e de desenvolvimento urbano das cidades. Essas políticas determinam em larga medida a facilidade com a qual pessoas de diferentes grupos sociais e níveis de renda conseguem acessar oportunidades de

20. Combes et al. (2012) mostram que os ganhos de aglomeração explicam o melhor desempenho de firmas localizadas em cidades maiores, em oposição a teorias alternativas de maior competição e seleção de firmas mais produtivas. 
emprego, serviços de saúde e educação, lazer etc. Assim, são políticas que têm papel-chave no funcionamento da economia, na construção de cidades mais sustentáveis e inclusivas e na redução da desigualdade de acesso a oportunidades.

Investimentos em infraestrutura de transporte podem diminuir custos de transporte e aumentar a integração de mercados de trabalho e de serviços, gerando economias de aglomeraçáo e impactos positivos sobre a produtividade na economia (Chatman e Noland, 2014; Gibbons et al., 2019; Haddad et al., 2015). Gibbons et al. (2019), por exemplo, encontram efeito direto do aumento da acessibilidade sobre o crescimento de empregos, basicamente pela entrada de novas firmas. De acordo com a estimativa dos autores, o aumento de $1 \%$ na acessibilidade gera um incremento de $0,3 \%$ a $0,5 \%$ de empregos. Mais ainda, apesar de firmas já existentes não ampliarem a quantidade de empregos, há um crescimento no total de produto por trabalhador e elevaçáo de salários. Haddad et al. (2015) mostram impacto positivo das linhas de metrô na cidade de São Paulo, e estimam que somente os efeitos de ganhos de produtividade seriam responsáveis por quase $65 \%$ do custo da obra e, mais interessante, que o efeito destes ganhos estaria distribuído em diversos municípios. O município de Sáo Paulo concentraria apenas 32\% do total desse impacto.

Medidas de gestão urbana e alguns instrumentos disponíveis para essa gestão, como a outorga onerosa, podem ser utilizados no financiamento de projetos de acessibilidade e saneamento. Contudo, é importante evitar eventuais capturas de alocaçáo de recursos. Uma vez que áreas sujeitas à outorga onerosa são regiōes mais valorizadas da cidade, há uma tendência para que a influência política aloque os recursos arrecadados para essas áreas já valorizadas. É preciso garantir que esses recursos sejam alocados para projetos com maior retorno social possível.

Outra intervenção que pode contribuir para redução de desemprego e possivelmente para melhoria de produtividade é a redução do custo de procura de novas ocupações. A melhoria de sistema de intermediação de máo de obra, eventualmente com parcerias entre o setor privado e o sistema público, é uma ação bastante desejável e também já em curso no Ministério da Economia, com o redesenho do Sistema Nacional de Emprego (SINE). O Ceará tem uma tradição de um bom sistema público de intermediação de mão de obra. Startups e setor público podem estabelecer parcerias para facilitar a procura de novas vagas e para que as empresas encontrem trabalhadores com qualificaçóes adequadas para as vagas abertas. Um melhor matching reduz rotatividade, pode ampliar o acúmulo de conhecimento específico e estimular políticas de treinamento.

Ações de segurança pública são destacadas pelo PRDNE, produzido pela Sudene. Diante do aumento de homicídios no Nordeste e da ampliação do crime organizado, é importante que um plano de desenvolvimento conceba açôes para mitigar esses efeitos negativos sobre o bem-estar da população, que afeta jovens em idade ativa, em geral, vítimas desse aumento da criminalidade.

A ampliação e integração de rede e sistema de cidades do Nordeste são ações também citadas no PRDNE. O plano propôe intervençôes tendo como base a já existente rede de cidades, e utiliza esse instrumento de planejamento territorial como forma de ordenação. O objetivo é criar um sistema policêntrico de cidades, onde haja um fluxo tanto entre as cidades-polo quanto na regiâo de influência da cidade-polo. Assim, tendo o território e esse sistema policêntrico como um norte, é possível ordenar e organizar projetos de infraestrutura e apoio aos arranjos produtivos locais, com a maximização de impactos no entorno de 
investimentos em curso ou já existentes. Com a ampliação de universidades e institutos federais na região, essa interligação e aumento de fluxo de ideias tornam-se ainda mais relevantes, com potencial de forte impacto e maximizaçáo das economias de aglomeraçáo.

\subsection{Inovação tecnológica e adoção de novas tecnologias}

Alguns dos principais objetivos debatidos na discussão sobre inovação tecnológica e adoção de novas tecnologias são o compartilhamento de risco, a ampliaçáo do setor privado no financiamento de ciência, tecnologia e inovação (CT\&I) e o maior foco no resultado, com uma interação maior entre universidade/institutos de pesquisa e empresas. A ampliação de formas de intervenção tem sido possível com a alteração do marco legal no setor. Assim, de acordo com esses princípios, algumas diretrizes podem ser listadas, conforme a seguir.

- Maior cooperação com universidades e institutos de pesquisa.

- Uso de poder de compra do estado para ampliar a atividade de pesquisa e desenvolvimento, por exemplo, em áreas de saúde, energia e infraestrutura. Há espaço para articulação federativa permitindo soluçôes de impacto na regiáo. $\mathrm{O}$ uso de contratos ou compras futuras do setor público, como garantidor de resultado de pesquisa e inovação, é um grande estímulo, podendo ser adotado pelos governadores do Nordeste no âmbito do Consórcio dos Governos do Nordeste.

- O novo marco regulatório de CT\&I permite iniciativas inovadoras, como a Empresa Brasileira de Pesquisa e Inovação Industrial (EMBRAPII), e soluçóes simples, como o compartilhamento do financiamento de laboratórios e instalaçóes. ${ }^{21}$ Atualmente, existem cinco representaçōes da EMBRAPII no Nordeste: Fortaleza, Salvador, Recife, João Pessoa e Campina Grande. Em Recife, por exemplo, o escritório da EMBRAPII tem se dedicado à internet das coisas (internet of things - Io T), com projetos inovadores na área de saúde (monitoramento do nível de oxigênio em cilindros para pacientes com doenças pulmonares graves), dentro do parque tecnológico do Porto Digital, uma experiência de sucesso com dinâmica de criação de empresas inovadoras, inclusive na aceleração e inserção das empresas no mercado. Em João Pessoa e Campina Grande, os projetos incluem diversas ações em automação industrial e robotização de linhas de montagem e açóes de ciência de dados e big data. ${ }^{22}$ Salvador e Fortaleza também englobam diversas aplicaçóes na área de saúde e mobilidade, automação e internet das coisas. Interessante observar que as diversas unidades têm prestado atendimento em nível nacional, assistindo empresas no Sul e Sudeste.

\subsection{Uso de energia renovável: eólica e solar}

A regiấo Nordeste tem apresentado uma expansão acelerada de geração de energias renováveis, tanto solar como eólica. Devido à elevada insolação, o semiárido brasileiro tem uma posição privilegiada para a captação de energia solar e, dessa forma, possui grande potencial de geração fotovoltaica (geração de energia elétrica por meio de materiais semicondutores) no Brasil. Em relação à geração de energia eólica, foram gerados 46,47 TWh por esta fonte em 2018. Em comparação com 2017, a produção foi superior em 14,8\%. Em termos de representatividade e abastecimento, a geração verificada pela fonte eólica foi responsável por 8,60\% na média de toda a geração injetada no Sistema Interligado Nacional (SIN) em 2018.

A regiāo Nordeste possui a maior representatividade na geração de energia por fonte eólica no Brasil, com $85,4 \%$ do total. A segunda colocada é a região Sul, com 12,4\%. A região

21. Ver trabalho de De Negri (2015) para mais informações.

22. Mais detalhes disponíveis em: <https://embrapii.org.br/unidades/ceei-centro-de-engenharia-eletrica-e-informatica-ufcg/>. 
Norte possui baixa representatividade, mas apresentou o maior crescimento relativo entre 2017 e 2018.

Os cinco estados com maior geraçáo em 2018 foram: Rio Grande do Norte (13,64 TWh), Bahia (11 TWh), Piauí (5,59 TWh), Rio Grande do Sul (5,56 TWh) e Ceará (5,53 TWh). Ainda nesse ano, foram instalados 74 novos parques eólicos, totalizando um potencial de fornecimento de 1,94 GW. Os estados contemplados com os novos empreendimentos foram Bahia, Rio Grande do Norte, Piauí, Ceará e Maranhão.

O ano de 2018 terminou com 583 usinas no total e 14,71 GW de potência eólica instalada, o que representou um crescimento de $15,19 \%$ de potência em relaçáo a dezembro de 2017, quando a capacidade instalada era de 12,77 GW. Considerando todas as fontes de geração de energia elétrica, em 2018, foram instalados 6,37 GW de potência, cujo crescimento foi liderado principalmente pelas fontes hidrelétrica e eólica, que representaram 47,55\% e $30,42 \%$ do total, respectivamente. Acrescido de 1,94 GW de nova capacidade instalada, o total eólico permitiu para a fonte uma participação de $9 \%$ na matriz elétrica brasileira.

\subsection{Melhorias na agricultura}

Conforme destacado, a agricultura é bastante heterogênea no Nordeste, com distintas realidades. Os princípios gerais para atuação no setor estão descritos nas subseçôes a seguir.

\subsubsection{Aprimoramento de assistência técnica e difusão de melhores práticas}

Dada a baixa qualificação dos produtores, o menor uso de adubos e defensivos e mesmo a menor presença da assistência técnica na região, a ampliação da atividade de extensionismo e assistência técnica pode ter um impacto direto e um custo reduzido para o Estado, considerando que tal assistência reduziria perdas na produção, elevaria a produtividade e a renda dos produtores rurais e finalmente haveria uma reduçáo do risco de crédito. Assim, é possível pensar um programa financiado, em parte ou mesmo em sua totalidade, pela reduçáo do risco de crédito. É possível desenhar algumas parcerias em estados onde a Empresa de Assistência Técnica e Extensão Rural (Emater) estiver presente e ativa, mas também se pode pensar em institutos federais ou instituiçôes de ensino da região. Ao mesmo tempo, a remuneração ou parte da remuneração dos extensionistas poderia ser pensada com uma correlação com o desempenho das atividades ou com prêmios para os melhores resultados, assim o profissional teria incentivos para a melhoria da produção, o produtor seria beneficiado pelo aumento dessa produção e a instituição de crédito teria o risco reduzido.

\subsubsection{Ampliação do cooperativismo ou associativismo de forma a se ganhar escala e aumentar a difusão de melhores práticas}

Diversas iniciativas já estão em curso nesse sentido, por exemplo, a identificação de arranjos produtivos locais, a ampliação de governança no território, entre outras. Especialmente em regiōes mais atrasadas, seria fundamental esse processo de organização social para mitigar riscos e compartilhar boas práticas.

\subsubsection{Ampliação de infraestruturas locais}

Pequenas obras de ligaçôes vicinais, conexôes à rede geral ou mesmo pequenas obras de armazenamento podem ter impacto significativo localmente. É necessário mapear e ordenar intervençôes com maior retorno social e econômico e desenhar uma forma de financiamento para estes investimentos (uma possível fonte seria usar recursos do Fundo de Desenvolvimento 
do Nordeste - FDNE), ou, ainda, realizar um desenho de parcerias com o setor privado para complementar o investimento nessas obras.

\subsubsection{Criação de estratégias de diferenciação de produtos e realização mais ampla de} intervenções conjuntas na linha das Rotas de Integração Nacional do MDR

É preciso pensar em intervençôes focadas em setores específicos, identificando potenciais e indústrias já instaladas (políticas verticais). O MDR tem mapeado, juntamente com uma série de pesquisadores da Academia, alguns desses arranjos produtivos locais, como caprinocultura, mel, açaí etc. O chamado programa Rotas de Integração Nacional visa entender localmente a produção e coordenar instrumentos como crédito, fundos constitucionais ou mesmo o Pronaf. O objetivo explícito é o de ampliar os elos na cadeia produtiva, estimular o associativismo como forma de ganhos de escala local, melhorar canais de comercializaçáo, ampliar estratégias para a diferenciação de produto, como melhorias sanitárias e selo de origem controlada, entre outros. ${ }^{23} \mathrm{Um}$ exemplo interessante do impacto de certificaçóes sobre o preço dos produtos produzidos em cadeias produtivas específicas é o da produção de camaráo, cuja certificação e selos de conformidades sanitárias ampliaram os mercados e elevaram o preço das empresas que se adequaram às regras, gerando um sobrepreço de até 40\% (Tahim e Araújo Júnior, 2014).

Essas iniciativas estão presentes, inclusive com boa inserção internacional e ampliação de renda e produtividade, em ramos específicos, mas como destacam Tahim e Araújo Júnior (2014), a maneira como essa inserção se dá nessas cadeias produtivas afeta a distribuição do valor adicionado. Quando os produtores não dominam cadeias de distribuição ou comercialização, eles não conseguem agregar valor localmente, isto é, a maior parte do rendimento não é apropriada pelo local. Este seria o caso da produção na qual o comprador possui um maior poder de mercado e os ganhos locais sáo menores. Em contrapartida, quando os produtores locais conseguem diferenciar o produto e agregar valor a ele, os ganhos e participaçáo nessa cadeia de valor se ampliam.

De toda forma, iniciativas desse tipo, assim como mapear e apoiar essas formas de produção especializadas localmente, podem alterar produçóes quase de subsistência e iniciar uma dinâmica local positiva, com a criação de laticínios locais e centro de processamento de carne e outros, por exemplo, na cadeia da caprinocultura. Essa iniciativa do MDR pode ser uma boa base para se avaliar o sucesso do tipo de intervenção.

\subsection{Melhorias institucionais e de instrumentos de política regional com ações para um federalismo cooperativo}

É fundamental aprimorar e aperfeiçoar mecanismos atuais de incentivo fiscal, não apenas tentando uma maior aproximação dos instrumentos de crédito com os objetivos maiores da política de desenvolvimento regional. A criação de condicionantes para a obtenção do crédito torna-se, portanto, um aspecto importante.

Em alguns momentos, o montante de emprego a ser gerado foi colocado como um critério para definiçáo de quem seria o tomador do crédito. No entanto, tal mecanismo pode e deve ser aperfeiçoado no sentido de oferecer ao tomador de crédito um menu de escolha de condicionalidades, como metas para treinamento de máo de obra, ampliaçáo da participação da empresa no exterior com aumento de exportaçáo ou mesmo metas de melhoria

23. Um dos setores promissores parece ser o de caprinocultura, em que o produtor local, segundo o MDR, tem custo de produção competitivo em relação ao produto importado, por exemplo, do Uruguai. 
de produtividade. Poderia ser pensado um desenho no qual o tomador de empréstimos recebesse prêmios por atingimento das metas e puniçôes do tipo redução de incentivos nas taxas dos empréstimos em caso de não cumprimento dos objetivos inicialmente acordados. É fundamental também melhorar e ampliar a avaliação e o acompanhamento de firmas beneficiadas pelos instrumentos de política regional, pois somente desta maneira será possível ajustar eventuais erros ou projetos menos exitosos.

A iniciativa de um consórcio interestadual é um passo bastante importante para o avanço na direção de uma Federação mais cooperativa e com açôes coordenadas com ganhos para todos os participantes. Assim, pode-se pensar não somente na cooperação para construção de projetos e planos conjuntos de infraestrutura, como também em externalidades advindas de projetos já em curso na região. Há uma necessidade de realização de pequenas obras de ligação local a grandes investimentos, como a Transnordestina e a transposição do rio São Francisco, que podem ter grande impacto local. Um desenho de financiamento em conjunto destas ligaçóes e obras vicinais pode ser parte desse grande federalismo cooperativo.

\subsection{Políticas educacionais e de treinamento de mão de obra}

Como já ressaltado anteriormente, houve um aumento na escolaridade da região, mas os índices de qualidade e mesmo o estoque absoluto de capital humano para pessoas com 25 anos ou mais, proxy para qualidade da mão obra, ainda ficam abaixo da média. Há uma extensa rede de escolas, universidades federais e institutos de pesquisa com muita capilaridade na regiáo que deve ser levada em conta em uma política para ampliação do impacto sobre a qualificação das mãos de obra, assim como o Sistema $S$ pode também ter um papel preponderante na interação com a melhoria dessa qualidade. A alteração dos mecanismos de concessão de empréstimos pelo Fundo Constitucional de Financiamento do Nordeste (FNE), em especial, pode ajudar a melhorar o treinamento e a capacitação da máo de obra, de maneira que a participação do sistema $S$ nesse processo pode ser decisiva para ganhos de escala e intercâmbio de conhecimento entre trabalhadores de setores e firmas distintas.

A ampliação da qualidade do ensino, a redução de evasão e a melhoria de testes padronizados são alguns dos resultados já obtidos por estados na região. É fundamental verificar quais açôes nesses estados poderiam ser replicadas para outras regiốes, como forma de melhorar a qualidade do ensino.

\subsection{Avaliação da infraestrutura e do futuro dos investimentos realizados na região: logística e transporte}

A consolidação de alguns grandes portos na região, aliada a um aumento da participação no comércio exterior, devido à expansão de áreas de cultivo de grãos para exportação, abre portas para a ampliaçáo de serviços e empresas de logística e transporte. Torna-se, assim, um desafio pensar o escoamento da produção, a armazenagem e a distribuição de bens e serviços produzidos na região.

Diversos investimentos já foram realizados na região, alguns inconclusos, sendo importante avaliar quais são os seus impactos, assim como há a necessidade de se considerar que o custo de abandonar projetos seria menos vantajoso para a sociedade do que a sua conclusão. Ademais, é preciso realizar análises que levem em conta a necessidade de ligaçôes adicionais para que o entorno desses grandes investimentos possa também ser beneficiado. $\mathrm{O}$ caso mais marcante neste aspecto é o projeto da transposição. 


\section{CONSIDERAÇÕES FINAIS}

Políticas regionais têm sido bastante criticadas no Brasil pela ausência de coordenação entre os seus objetivos gerais e a implementaçáo dos instrumentos, por exemplo, a Política Nacional de Desenvolvimento Regional, em 2007, foi estabelecida por decreto, a criação da Sudene, estabelecida em lei, e os instrumentos de política regional explícita têm regramento constitucional. Obviamente, esta não é a fonte principal do descasamento entre os objetivos e as açôes na ponta, mas demonstra as dificuldades dessa ação.

Conforme destacado, a Sudene já submeteu ao Congresso Nacional um plano de desenvolvimento para o Nordeste, de maneira que este artigo traz sugestóes para a discussáo regional, acreditando serem complementares a açôes já em curso. São sete as sugestóes agrupadas nos temas destacados a seguir.

1) Ampliaçẫo deganhos de aglomeração e mitigação de efeitos negativos de congestionamento.

2) Inovação tecnológica e adoção de novas tecnologias.

3) Uso de energia renovável: eólica e solar.

4) Melhorias na agricultura, calcadas em quatro pilares: $i$ ) aprimoramento de assistência técnica e difusão de melhores práticas; ii) ampliação do cooperativismo ou associativismo de forma a se ganhar escala e aumentar a difusão de melhores práticas; iii) ampliação de infraestruturas locais; e iv) criação de estratégias de diferenciação de produtos e realização mais ampla de intervençôes conjuntas na linha das Rotas de Integração Nacional do MDR.

5) Melhorias institucionais e de instrumentos de política regional com açóes para um federalismo cooperativo.

6) Políticas educacionais e de treinamento de mão de obra.

7) Avaliação da infraestrutura e do futuro dos investimentos realizados na região: logística e transporte.

A lenta convergência de níveis de renda deve ser levada em conta, como também o fato de que políticas em nível nacional de melhoria de produtividade, mesmo se bem-sucedidas, não serão suficientes para em dez anos fazer com que a região atinja o limite de $75 \%$ do PIB per capita nacional. Em um horizonte até 2030, dentro dessas simulaçôes de melhoria de produtividade, o PIB do Ceará cresceria acima da média brasileira, contudo, o PIB per capita do estado, ainda assim, neste último ano da série, seria de aproximadamente 55\% do PIB per capita do Brasil. Assim, açôes ativas podem ser pensadas para que esse processo de convergência de atividades seja mais acelerado e para que a regiáo Nordeste possa como um todo efetivamente suplantar os níveis de defasagem em relação à economia nacional. Deve-se também lembrar que as políticas de transferência de renda ou o Programa Cisternas tiveram grande impacto sobre o bem-estar da população, devido à concentração espacial da pobreza. Políticas focadas na pobreza, obviamente, beneficiam mais as regióes mais pobres, e como tal devem ser continuadas. Da mesma forma, as políticas regionais podem e devem ser pensadas para reduzir diferenciais de renda entre os estados brasileiros.

\section{REFERÊNCIAS}

BANCO MUNDIAL. A geografia econômica em transformaçáo. Washington: Banco Mundial, 2009. (Relatório sobre o Desenvolvimento Mundial). Disponível em: <https:// openknowledge.worldbank.org/bitstream/handle/10986/5991/WDR\%202009\%20-\%20 Portuguese. pdf?sequence $=6$ \&isAllowed $=y>$. 
BRANCO, D.; FÉRES, J. G. Raindrops for education: drought shocks and school performance in Brazilian rural schools. In: ENCONTRO REGIONAL DA ASSOCIAÇÃO NACIONAL DOS CENTROS DE PÓS-GRADUAÇÃO EM ECONOMIA, 24., 2019, Fortaleza, Ceará. Anais... [s.l.]: Anpec, 2019.

BRASIL. Plano Regional de Desenvolvimento do Nordeste. Recife: Sudene/MDR, 2019.

CASTRO, C. N. A agricultura no Nordeste brasileiro: oportunidades e limitaçôes ao desenvolvimento. Brasília: Ipea, 2012. (Texto para Discussão, n. 1786).

Sobre a agricultura irrigada no semiárido: uma análise histórica e atual sobre diferentes opçôes de política. Brasília: Ipea, 2018. (Texto para Discussão, n. 2369).

CASTRO, C. N.; RESENDE, G. M.; PIRES, M. J. S. Avaliaçáo dos impactos regionais do Programa Nacional da Agricultura Familiar (Pronaf). Brasília: Ipea, 2014. (Texto para Discussão, n. 1974).

CHARLOT, S. et al. Agglomeration and welfare: the core-periphery model in the light of Bentham, Kaldor, and Rawls. Journal of Public Economics, v. 90, n. 1/2, p. 325-347, 2006.

CHATMAN, D. G.; NOLAND, R. B. Transit service, physical agglomeration and productivity in US metropolitan areas. Urban Studies, v. 51, n. 5, p. 917-937, 2014.

COELHO, V. A PNDR e a nova fronteira do desenvolvimento regional brasileiro. Boletim Regional, Urbano e Ambiental, Brasília, n. 17, 2017.

COMBES, P. et al. The productivity advantages of large cities: distinguishing agglomeration from firm selection. Econometrica, v. 80, n. 6, Nov. 2012.

CRUZ, B. Dinâmica recente dos PIBs per capita regionais: quanto tempo para chegar a 75\% do PIB per capita nacional? Boletim Regional, Urbano e Ambiental, n. 9, p. 83-92, 2014.

DE NEGRI, F. Inovação e produtividade: por uma renovada agenda de políticas públicas. Radar, n. 42, dez. 2015.

FERREYRA, M.; ROBERTS, M. (Ed.). Raising the bar for productive cities in Latin America and the Caribbean. Washington: World Bank Group, 2018.

GIBBONS, S. et al. New road infrastructure: the effects on firms. Journal of Urban Economics, v. 110, p. 35-50, 2019.

HADDAD, E. A. et al. The underground economy: tracking the higher-order economic impacts of the São Paulo Subway System. Transportation Research Part A: Policy and Practice, v. 73, p. 18-30, 2015.

MONTEIRO NETO, A.; SILVA, R. O. Desconcentraçáo territorial e reestruturaçáo regressiva da indústria no Brasil: padrōes e ritmos. Brasília: Ipea, ago. 2018. (Texto para Discussão, n. 2402).

PESSOA, S. Existe um problema regional no Brasil? In: ENCONTRO NACIONAL DA ASSOCIAÇÃO NACIONAL DOS CENTROS DE PÓS-GRADUAÇÃO EM ECONOMIA, 25., 1997, Recife, Pernambuco. Anais... [s.l.]: Anpec, 1997.

PRAGER, J.; THISSE, J. Les enjeux géographiques du développement économieque. [s.l.]: AFD, 2009. (Notes et Documents, n. 46).

TAHIM, E.; ARAÚJO JÚNIOR, I. A carcinicultura do Nordeste brasileiro e sua inserção em cadeias globais de produção: foco nos APLs do Ceará. Revista de Economia e Sociologia Rural, Piracicaba, São Paulo, v. 52, n. 3, p. 567-586, jul./set. 2014. 
TCU - TRIBUNAL DE CONTAS DA UNIÃO. Relatório de levantamento do Programa de Promoção da Sustentabilidade de Espaços Sub-Regionais (PROMESO). Brasília: TCU, 2009.

ZACKSESKI, N.; OLIVEIRA, C. Investimentos federais do Brasil 2002-2016: análise regional e estadual. [s.l.]: Ipea. (Relatório de Pesquisa). No prelo.

\section{BIBLIOGRAFIA COMPLEMENTAR}

BRASIL. Lei no 11.326 , de 24 de julho de 2006. Estabelece as diretrizes para a formulaçáo da Política Nacional da Agricultura Familiar e Empreendimentos Familiares Rurais. Diário Oficial da União, Brasília, 25 jul. 2006.

. Ministério da Integração Nacional. A irrigação no Brasil: situação e diretrizes. Brasília: MI; IICA, 2008. 132 p.

Decreto no 9.064, de 31 de maio de 2017. Dispóe sobre a Unidade Familiar de Produção Agrária, institui o Cadastro Nacional da Agricultura Familiar e regulamenta a Lei no 11.326, de 24 de julho de 2006, que estabelece as diretrizes para a formulaçáo da Política Nacional da Agricultura Familiar e empreendimentos familiares rurais. Diário Oficial da União, Brasília, p. 11, 31 maio 2017. Seção 1.

Ministério Integraçáo Nacional. Portaria no 80, de 28 de fevereiro de 2018. Estabelece as Rotas de Integração Nacional como estratégia de desenvolvimento regional e inclusão produtiva do Ministério da Integração Nacional. Diário Oficial da Uniáo, Brasília, p. 40-53, 1o mar. 2018. Seção 1.

CASTRO, C. N.; PEREIRA, C. N. Agricultura familiar, assistência técnica e extensáo rural e a política nacional de Ater. Brasília: Ipea, 2017. (Texto para Discussão, n. 2343).

CERVERO, R.; SANDOVAL, O.; LANDIS, J. Transportation as a stimulus of welfare-to-work private versus public mobility. Journal of Planning Education and Research, v. 22, n. 1, p. 50-63, 2002.

IBGE - INSTITUTO BRASILEIRO DE GEOGRAFIA E ESTATÍSTICA. Censo agropecuário 2006: Brasil, grandes regiōes e Unidades da Federação. Rio de Janeiro: IBGE, 2009. 775 p.

. Censo agropecuário 2017. Rio de Janeiro: IBGE, 2019.

PEREIRA, C.; CASTRO, C. O Sistema Nacional de Pesquisa Agropecuária: histórico, estrutura e financiamento. Brasília: Ipea, 2017. (Texto para Discussão, n. 2338).

PEREIRA, C.; CASTRO, C.; PORCIONATO, G. Dinâmica econômica, infraestrutura e logística no Matopiba. Brasília: Ipea, 2018. (Texto para Discussão, n. 2382).

PEREIRA, R. H. M. et al. Desigualdades socioespaciais de acesso a oportunidades nas cidades brasileiras. Rio de Janeiro: Ipea, 2019. (Texto para Discussão, n. 2535).

PORCIONATO, G. L.; CASTRO, C. N.; PEREIRA, C. N. Aspectos sociais do Matopiba: análise sobre o desenvolvimento humano e a vulnerabilidade social. Brasília: Ipea, 2018. (Texto para Discussão, n. 2387).

RESENDE, G. et al. Fatos recentes do desenvolvimento regional no Brasil. In: RESENDE, G. (Ed.). Avaliação de políticcas públicas no Brasil: uma análise de seus impactos regionais. Rio de Janeiro: Ipea, 2014. cap. 1.

STOKES, E. C.; SETO, K. C. Tradeoffs in environmental and equity gains from job accessibility. Proceedings of the National Academy of Sciences, v. 115, n. 42, p. 9773-9781, 2018. 
